\title{
Antisemitismo canino en las Coplas del perro de Alba
}

\author{
Adrienne L. Martín \\ Universidad de California, Davis
}

Título: Antisemitismo canino en las Coplas del perro de Alba.

Resumen: El objetivo principal de este trabajo es abordar el estudio de las Coplas del perro de $A l b a$, un texto olvidado hasta el momento por la mayor parte de la crítica, en relación con su cariz marcadamente antisemitista, el cual permite relacionarlo con numerosos textos posteriores de nuestra literatura. El alejamiento de los topoi comunes en este tipo de sátiras, la incorporación de la figura del can como principal enemigo de los judíos y la dignificación casi heroica del mismo, hacen de este texto, a pesar de su escaso mérito estético-literario, un testimonio de primera fila de las problemáticas interacciones sociales de la España del momento $y$, tal vez, también de la época moderna.

Palabras clave: Sátira, Literatura antisemita, Siglo de Oro, perros, Coplas del perro del Alba.

Fecha de recepción: 24/4/2014.

Fecha de aceptación: 11/6/2014.
Title: Canine Antisemitism in the Coplas del perro de Alba.

Abstract: The main objective of this essay is to bring to light and examine the Coplas del perro de Alba, a text that until now has been overlooked by critics, whereas its anti-Semitism allows us to relate it to subsequent texts. Moreover, the poem's distancing from conventional satirical topoi, its incorporation of the dog as a principal enemy of the Jews, and its corresponding elevation of that animal to an almost heroic level permit its interpretation as an emblem of the problematic social interactions in Spain during that time, and even in the modern era.

Key words: Satire, anti-Semitic literature, Golden Age, dogs, Coplas del perro del Alba.

Date of Receipt: 24/4/2014.

Date of Approval: 11/6/2014. 
¡Guay de la Ley de Moysén que nosotros tanto honramos! Que un perro, si bien miramos, della faze gran desdén.

En el cervantino Entremés de la elección de los alcaldes de Daganzo, el regidor Alonso Algarobilla afirma respecto al único converso que se encuentra entre los candidatos a alcalde:

Pues ¿Pedro de la Rana? No hay memoria que a la suya se iguale; en ella tiene del antiguo y famoso perro de Alba todas las coplas, sin que letra falte' ${ }^{1}$.

El hecho de que Rana tenga grabados en la memoria los versos de las Coplas del perro de Alba le merece el voto de Panduro y Estornudo en esa absurda elección entre tontos. Es significativo además que de los cuatro pretendientes a alcalde sea precisamente el converso el que pueda recitar de memoria los versos de esas coplas virulentamente antisemíticas.

También se antoja revelador que las referencias a estas infamantes y escandalosas letrillas octosilábicas no sean infrecuentes en la prosa y el drama (comedias y entremeses) del Siglo de Oro. Entre otras obras, son mencionadas en textos de Lope de Vega, Quiñones de Benavente, La picara Justina, y una exitosa comedia de Andrés de Claramonte publicada en 1638, El valiente negro en Flandes. En esta última, el protagonista, Juan de Mérida, es desdeñado como perro por el color de su tez, hasta que por su heroicidad el duque de Alba le asienta la plaza en su compañía de Flandes y le da su apellido, convirtiéndolo en Juan de Alba². De ahí los constantes juegos de palabras con "negro / blanco" o "negro / alba", como el contenido en la expresión de gratitud del soldado:

1 Miguel de Cervantes, Entremeses, ed. Antonio Rey Hazas, Madrid, Alianza, 2006, p. 91.

2 Los envidiosos enemigos de Juan, el Capitán Agustín, el Alférez y el Sargento, le llaman constantemente "perro" o "perrazo" y sus acciones se definen como "perrerías". 
Pues me dais

segunda naturaleza,

y soy negro y alba soy,

corrido de vuestras perlas

el perro de Alba seré

de las escuadras flamencas ${ }^{3}$.

Al declararse "perro de Alba" de los flamencos, asume y enarbola su doble condición: canina y minoritaria, afirmándose también en su función de perseguidor implacable del enemigo y defensor de la honra espańola. Cuando el duque piensa retirarse ante las fuerzas del Príncipe de Orange, Juan se ofrece para perseguir al enemigo, afirmando al de Alba: "El Perro de Alba soy, vengan judíos / [...] Gran señor, soy perro, / y así muerdo con rabia"”.

Por otro lado, es obvio que el protagonista de las Coplas -el feroz perro que atacaba impunemente a los judíos de Alba de Tormes- era conocido por el público de los corrales. En su comedia, Claramonte utiliza la figura del perro de Alba como metáfora afirmativa del que acosa y castiga despiadadamente, o rabiosamente, en el caso de Juan de Alba, al enemigo. Evidentemente, en aquellos ańos las coplas eran notorias, y si su protagonista podía conceptuarse positivamente, las Coplas, por su parte, se mencionaban para indicar algo de mínimo o nulo valor estético, para señalar a una persona agresivamente antisemítica, o para motejar a alguien de judío o converso 5 .

Aunque el período histórico reflejado en las Coplas antedata la expulsión de 1492, la versión más antigua del poema es de 1524, cuando el

3 Andrés de Claramonte y Corroy, El valiente negro en Flandes, Alicante, Biblioteca Virtual Miguel de Cervantes, Biblioteca Nacional, 2010, Reproducción digital a partir de Parte treynta vna, de las meiores comedias, que hasta oy han salido, en Barcelona: en la Emprenta de Iayme Romeu: a costa de Iuan Sapera, 1638, p. 165v. Modernizo la ortografía y puntuación.

4 Ibidem, p. 169.

5 El conocido poeta burlesco del siglo XVI Antonio de Maluenda constata la nulidad estética de las Coplas al afirmar de sus propios versos: "Mis musas son musa musae; I mis coplas del perro de Alba". Véase J. H. Terlingen, "Un hispanista neerlandés del siglo XVII, Guiliam de Bay", en Homenaje a J. A. Van Praag, Amsterdam, L. J. Veen, 1956, p. 126. 
bachiller salmantino Juan Agüero de Trasmiera lo imprime en Medina del Campo. El poema aparece en el catálogo de la biblioteca de Hernán Colón bajo el título "Pleyto de los iudios contra el perro de alua en metro castellano", aunque, según Joseph Gillet, no se conserva copia de esa edición ${ }^{6}$. En dos artículos de los años 1920 Gillet reprodujo y editó un pliego suelto de las Coplas que se encuentra en la BNE (R9.495) ${ }^{7}$. Posteriormente, en 1981, Carlos Carrete Parrondo recopiló el mismo pliego de cordel en Fontes iudaeorum regni castellae, puntuando el texto, modernizando la ortografía y regularizando el uso de las mayúsculas ${ }^{8}$. El título del poema reza como sigue: "Este es el pleyto de los judíos con el perro de Alua, y de la burla que les hizo. Nuevamente trovado por el bachiller Juan de Trasmiera, residente en Salamanca, que hizo a ruego y pedimento de un señor". Cito entonces de la versión del texto publicado por Carrete Parrondo, e incluyo abajo el llamativo frontispicio del pliego de la BNE:

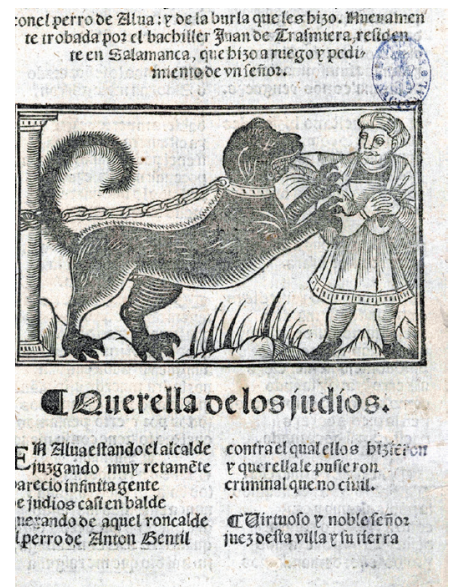

6 Catalogue of the Library of Ferdinand Columbus, reproducido por A.M. Huntington, New York, 1905.

7 Joseph E. Gillet, “The Coplas del Perro de Alba”, Modern Philology XXIII, 4 (1926), pp. 417-444 y Modern Philology XXVI, 1 (1928), pp. 123-128.

8 Carlos Carrete Parrondo, Fontes iudaeorum regni castellae I, Salamanca, Universidad Pontificia de Salamanca, 1981, pp. 35-41. Una lista de los varios pliegos sueltos que contienen versiones de las Coplas del perro de Alba y su procedencia se encuentra en Antonio Rodríguez Moñino, Diccionario de pliegos sueltos poéticos (siglo XVI), Madrid, Castalia, 1970, pp. 367-370, y en Carlos Carrete Parrondo, op. cit., y Joseph E. Gillet, op. cit. 
Que yo haya podido determinar hasta el momento, aparte de algunos comentarios breves dispersos, no se ha estudiado en profundidad el contenido de este poema, que en verdad arroja luz (aunque esta sea satírica y totalmente ofensiva) sobre la situación de los judíos y conversos antes de la expulsión. De esta manera las Coplas del perro de Alba tienen cierto parecido con las igualmente virulentas diatribas antisemíticas posteriores de Quevedo y otros, además de reiterar la hostilidad anti-judaica del momento, al igual que la tópica tradición satírico-burlesca que le da expresión?

El aspecto que más distingue este poema de otros similares es el hecho de que narra la historia de un perro antisemítico, en un tono que va desde la sorna y la épica burlesca al realismo más grotesco. Ahora bien, probablemente comparto con otros una larga experiencia con los canes, $y$ hasta ahora no me he topado con ninguno que sea abiertamente racista o antisemita. Una de las razones por las cuales estos animales son tan apreciados es precisamente porque no juzgan a las personas en virtud de raza, color de la tez, religión, inteligencia, atuendo, género sexual, profesión, ni ninguna otra categoría de las que los humanos utilizamos para distinguirnos de los demás y, como consecuencia, vivir en discordia constante. Obviamente, el perro no nombrado en el poema es un hábil sustituto, una pantalla jocosa si se quiere, para una mentalidad férreamente viejocristiana que a partir del siglo XIII (e incluso antes) veía a los judíos y conversos como indeseables, y por ende blanco de resentimientos, sátira $y$, en el mejor de los casos, de burla. La sátira antisemita de los humanos solía enfocarse sobre los percibidos rasgos físicos, régimen alimenticio, costumbres y ritos de los judíos, y en su presunta explotación usurera de los cristianos, práctica de la magia, supuestas profanaciones religiosas y engaños; todo lo cual culminó en el topos más apto para la época: el judío asesino de Cristo. Las Coplas no indagan en estos topoi convencionales, sin embargo, y explotan mayormente la figura del judío y el converso

9 Como bien sabemos, Quevedo lanzaba a menudo sonetadas contra Góngora en las que tachaba al rival de perro y judío. Véanse, por ejemplo, los célebres versos "Yo te untaré mis obras con tocino, / porque no me las muerdas, Gongorilla, / perro de los ingenios de Castilla, / doctor en pullas, cual mozo de camino". 
como ridículos cobardes, al extremo de que se dejan aterrorizar por un perro.

Estructuro el análisis alrededor de la trama del poema, dada la probabilidad de que relativamente pocos lo conozcan y no sea común dentro de los parámetros de este tipo de sátira. Me enfoco además hacia algunos pasajes en particular que lo distinguen de otros tratados antisemíticos, para rastrear lo que revela de la historia social de la aljama judía, y concluyo sugiriendo lo que pudiera contribuir al poema el elemento canino. El que las Coplas estén escritas en lenguaje del siglo XV con algunos vocablos en ladino, revela cierta familiaridad del autor con las peculiaridades del judeo-espańol y por esto pueden ser de interés para los lingüistas. Representan a la vez un desafío para editores y lectores porque la ortografía es inconsistente, la puntuación y las tildes inexistentes, las erratas numerosas, y por ende, a veces el sentido del texto puede resultar dudoso ${ }^{10}$.

El poema narra cómo los residentes de la comunidad judía de Alba de Tormes levantan una querella criminal ante el dayán ${ }^{11}$ Mosé Garçón, debida al comportamiento de un perro negro que pertenece a un tal Antón Gentil (nombre altamente significativo). Acusan al perro de atacar y morder a los judíos y amenazan con apelar al duque de Alba si el animal no es ajusticiado por sus acciones ${ }^{12}$. La queja empieza como sigue:
Nos, los que paz deseamos,
la noble aljama e caal, contra un perro natural desta villa nos quexamos, e a vos, señor, demandamos le colguéys de la picota,

10 Carrete Parrondo ofrece soluciones a algunos de estos retos en su edición.

11 El dayán (plural dayanim) era un juez laico elegido por los miembros principales de la comunidad judía. Véase al respecto Haim Beinart, "Hispano-Jewish Society", en Jewish Society Through the Ages, ed. H. H. Ben-Sasson y S. Ettinger, Londres, Vallentine-Mitchell, 1971, pp. 220-238 (p. 235).

12 Según la Encyclopaedia Judaica, los Fueros de Alba de Tormes fueron otorgados por Alfonso VII de Castilla en 1140 y estipulaban las relaciones entre judíos y cristianos, los cuales eran iguales ante la ley. La litigación entre los dos grupos ocurría en la sinagoga de la judería. Véase Jewish Virtual Library [http://www.jewishvirtuallibrary.org/jsource/Judaic a/ejud_0002_0001_0_00664.html]. 
porque nos muerde e destruye,

nunca de nosotros fuye,

e nos trae a la estricota. (copla núm. 5)

Es fascinante, pues, que el poema refleje ciertos aspectos de la vida de la aljama, vista desde dentro. Caal, del hebreo cahal, se aplica igualmente al lugar de reunión, templo o sinagoga, y a la congregación que se concita en él. En este caso, el vocablo se hace extensivo a la comunidad judía de Alba, confusa por el acoso del perro, que debe ser, al igual que su dueño, un perro "gentil", o sea, cristiano viejo. Nota aparte merece el hecho de que piden que el perro sea ahorcado, lo cual no debe sorprender, ya que se trata de una época en la que los criminales se sometían a la vergüenza pública y los animales ocasionalmente se llevaban a juicio y se ajusticiaban si, por ejemplo, accidental o deliberadamente, causaban la muerte de una persona o se encontraban entre las víctimas en casos de bestialismo.

Varios judíos testifican ante el juez sobre el comportamiento del perro; los primeros son Abrayme Abenarón y el maestre Ysaac, jubetero. Explican el comportamiento agresivo del can tal que así:

¡Oh, señor juez, y qué pena

tenemos ambos a dos,

que se va detrás de nos

quando le viene la vena!

Aunque vaya con cadena,

nos ladra e muerde este alano,

que cuando dél escapamos

todos, por cierto, pensamos

que el Dió lo tién con su mano (copla núm. 7)

Otro, Samuel, se queja porque el perro no deja de ladrar y de rasgarles los balandranes ${ }^{13}$. Lo anterior queda registrado en el grabado que decora el frontispicio del pliego suelto de la Biblioteca Nacional. En él aparece un tipo de simulacro de un judío en la persona vestida no con balandrán

13 Carmen Bernis, Trajes y modas en la España de los Reyes Católicos II, Los hombres, Madrid, CSIC, 1979, pp. 58-60, describe el balandrán como "Traje de encima con mangas, talar y holgado, abierto por delante de arriba abajo"; y añade que "todo parece indicar que el balandrán era siempre una ropa larga hasta los pies". 
sino con un sayo corto con pliegues, traje común durante el siglo XV, y turbante $^{14}$. Un perro de tamaño absolutamente desproporcionado, identificado por los acosados en el texto como un alano, está atacando al hombre. Imponente y feroz, de pecho y cabeza fuertes y anchos (como eran, por cierto, los alanos), es mucho más abultado que el hombre a quien amenaza. Las fauces y la dentadura (que parece más humana que animal, ya que no tiene colmillos) sujetan a su víctima mientras que el perro se inclina sobre él. Este perro de Alba se asemeja a algún animal fantástico de la tradición emblemática, con sus enormes patas y garras cuya forma no es para nada canina. Es más, con el pelo del lomo erizado y la cola curvada y elevada por encima, el perro está representado en una postura agresiva, y esta agresividad se acrecienta por estar sujeto a la cadena.

Después de la comparecencia de los querellantes, un grupo de conversos acuden como testigos: un zapatero, un herrero, y un médico, entre otros; todos ellos son ridiculizados. Cada uno cuenta cómo el perro le ha perseguido, atacado y lastimado, revelando con ello su propia cobardía y temor. Por ejemplo, Bezacó, el herrero, narra cómo el perro acosa maliciosamente a sus hijos, mordiéndoles, rasgándoles la ropa e inspirando tal pavor que todos se ensucian: "que si del perro fuymos / todas las calças hinchimos / sin podernos remediar" (copla núm. 18). Tales episodios escatológicos continúan cuando el físico, don Don, relata sus dolorosas experiencias con el perro:

Estando mirando orinas, dando purgas a dolientes y mirando inconuinientes sobre ciertas medicinas, si eran malas o eran finas, vino el gran perro detrás. Yo, luego, como le vi, el vientre libre sentí, que no tuue embargo más. (copla núm. 21)

14 En un correo electrónico personal, el profesor Norman Roth, experto en la materia, me comunica que no hay nada específicamente judío en el grabado aparte del turbante, que puede ser un intento anacrónico de darle una apariencia judía a la persona retratada. Además, los judíos españoles no llevaban turbantes en el siglo XV. 
Yo no hallé otro remedio para ciertos mis parientes no curando de simientes, para embargo e para thedio, saluo pongan este medio; que luego se soltarán (con reuerencia hablando), poco a poco deshinchando el enoxo dexarán. (copla núm. 22)

Este tipo de humor escatológico prevalece a través del poema y establece un eslabón incontrovertible entre judíos, conversos y excremento. La utilización del perro como laxante, por ejemplo, es una burla de la medicina practicada desde tiempos inmemoriales por los judíos. Un nombre basta para recordar la celebridad de los médicos judíos en la Espańa de la Edad Media y posterior: el cordobés Maimónides. Al respecto, en su fascinante estudio de la vida cotidiana de los judíos en la Edad Media, Norman Roth traza la historia de los médicos y apotecarios judeo-espańoles, apuntando que en Espańa hubo más médicos judíos en cualquier período que en el resto del mundo junto. Nos recuerda que a casi todos los reyes castellanos y aragoneses los atendían médicos judíos; de ahí que los Reyes Católicos tuvieran sus propios médicos personales pertenecientes a esa cultura ${ }^{15}$. Esta presunta costumbre de ayer y hoy de acudir preferentemente a médicos judíos está, quizás, al fondo de la burla del don Don de las Coplas, porque a pesar de la costumbre entre la nobleza y realeza de recurrir a doctores hebraicos, demuestra la desconfianza popular hacia ellos. Por todo esto, la escatología burlesca que encontramos en las Coplas del perro de Alba no se inclina hacia el estrato corpóreo bajo el que se afirma la vida, en términos de Bajtin; en vez de esto, sugiere la profanación de personas que generalmente eran vistas y representadas desde tiempos medievales como cobardes, sediciosas y usureras, cuando no sodomitas.

El momento más grotesco ocurre en el poema cuando un converso llamado Husillo afirma que el perro no solo le ha mordido en las nal-

15 Norman Roth, Daily Life of Jews in the Middle Ages, Westport, Connecticut, Greenwood Press, 2005, pp. 137-139. 
gas, sino que también interrumpió la ceremonia de la circuncisión de su hijo. Aunque el pasaje presenta ciertos problemas interpretativos, el texto sugiere que el perro entró en el templo cuando el rabino estaba circuncidando al hijo de Husillo, y acabado el rito, asió y probablemente ingirió el prepucio desechado:

\author{
El qual, en el templo estando, \\ como a mi fijuelo vio, \\ león brauo se mostró, \\ que estauan sabadeando. \\ Mi fijuelo, estando orando, \\ el rabí circuncidó; \\ luego en pies le vi poner \\ $\mathrm{y}$, con pésimo saber, \\ lo que el rabí dexó asió. (copla núm. 26)
}

La circuncisión del niño (Brit Milah) es un rito observado por la gran mayoría de los judíos -quizás el que más- entonces y ahora, en observancia del mandamiento de la Torá. En Génesis 17:10-14 y Levítico 12:3 se ordena que cada varón recién nacido sea circuncidado en el octavo día. El miembro viril circuncidado se considera signo externo del pacto entre los descendientes de Abraham y Dios, y es reconocimiento también de que la nación judía se perpetuará a través del varón circuncidado. De manera que este rito venerado y santificado con bendiciones, que contiene gran significado espiritual para los judíos, es corrompido en las Coplas de la manera más vil y monstruosa, y la ofensa es intensificada porque se sugiere que ocurre en el templo y en el día santo de Shabat (el texto especifica que "estauan sabadeando"). En vez del acostumbrado entierro en tierra $\mathrm{o}$ arena, el prepucio es profanado, al igual que el ritual, por el perro ${ }^{16}$. El episodio indica el extremo al cual la situación vital de los judíos españo-

16 Los chistes sobre circuncidados (o "retajados") no eran infrecuentes durante el Siglo de Oro. María de los Ángeles Hermosilla Álvarez, "Referencias antisemíticas en la literatura popular del Siglo de Oro", en Actas de las Jornadas de Estudios Sefardies, ed. Antonio Viudas Camarasa, Cáceres, Universidad de Extremadura, Instituto de Ciencias de la Educación, 1981, pp. 161-168 (p. 167), recoge una anécdota de Timoneda entre un capado y un judío: "Paseábase un músico tiple y capado, por delante de un ropavejero, famosísimo judío, viejo y relajado, el cual por burlarse 
les había llegado desde mediados del siglo XIII cuando, en las Partidas, Alfonso X el Sabio ordenó que "[...] porque la sinagoga es la casa donde se alaba el nombre de Dios, prohibimos a los cristianos que la degraden o saqueen; [...] prohibimos que impidan o molesten a los judíos en su estudio o cuando recen de acuerdo a su ley" ${ }^{17}$.

Por otra parte, la antipatía que sentían los judíos por los perros posee larga tradición, como apunta Judah Elijah Schochet sobre las imágenes de perros que aparecen en el Viejo Testamento:

The dog is one of the few animals almost invariably spoken of in negative and derogatory terms. There apparently was little personal relationship between biblical man and the dog. [...] Dogs are described as being noisy (Psalms 59:7-14), greedy (Isaiah 56:10), stupid (Isaiah 56:10) filthy (Proverbs 26:11) [...] the term "dog" is applied as an insult to humans [1 Kings 22:38 ${ }^{18}$.

Parece evidente que el término operante, en términos de actitudes semíticas históricas hacia los canes, es "sucio" o "inmundo". Debemos también recordar uno de los insultos más graves que se aplicaba a los judíos en la Espańa de la temprana época moderna y que parece persistir entre los antisemitas empedernidos aun hoy: perro judío ${ }^{19}$. También, como ha apuntado Mark Levenson -autor judío que se declara simpatizante de los perros-, más allá de la teología y el sentido práctico, hay razones viscerales para que sean anti-caninos los judíos. Desde las Cruzadas hasta los pogromos y al Holocausto, las relaciones entre judíos y perros suelen consistir en que los primeros huyen de las fauces de los últimos, azuzados por sus perseguidores antisemitas. Si los judíos tienen un recuerdo racial de los

del músico le dijo: «¿Señor, cómo le va a su gavilán sin cascabeles?» Respondió el capado: "como al de vuesa merced sin capirote»".

17 Citado en Evelyne Kenig, Historia de los judios españoles hasta 1492, Barcelona, Paidós, 1995, p. 21.

18 Judah Elijah Schochet, Animal Life in Jewish Tradition, New York, Ktav, 1984, pp. 37-38.

19 Sobre la imagen medieval divulgada por cristianos de los judíos como perros, y las fuentes bíblicas de esta simbología, véase Kenneth Stow, Jewish Dogs. An Image and Its Interpreters. Continuity in the Catholic-Jewish Encounter, Stanford, California, Stanford University Press, 2006. 
perros, no es un recuerdo feliz ${ }^{20}$. Dada esta triste relación entre judíos y canes, la estructura y el contenido del poema cobran más sentido.

Volviendo a las Coplas, el perro es detenido, sentenciado a muerte y enviado a la sinagoga para ser ahorcado y quemado, y sus restos arrojados a un lago en un acto de venganza y expiación pública. La población judía de Alba recibe la sentencia con jubilación, agradeciéndole a Dios la merced hecha. Pero el furioso perro logra escaparse de la horca, alborotándose y matando a varios judíos y finalmente acogiéndose a sagrado ("en sagrado entró”). Los judíos que quedan huyen a Oviedo, dejando al temido perro a salvo para atacar salvajemente a los pocos judíos que permanecen en Alba, rasgando sus vestiduras acostumbradas, interrumpiendo sus ceremonias y mordiendo y cebándose con orejas y narices. La insistencia textual en ese último acto pone de relieve el convencional objeto de burlas antisemíticas: la (desmesurada) nariz judía ${ }^{21}$. Pero el perro no se limita a arrancar orejas y narices, porque también logra castrar (acto que anula la continuación de la prole) a un tal Salomón y a sus dos hijos (copla núm. 44).

Eventualmente el perro muere de pestilencia, es enterrado con honores y se le erige una tumba con inscripciones apropiadas para acomodar sus restos:

Después de todo pasado, cayó el perro en gran dolencia, e de mal de pestilencia fue desta vida sacado.

El qual fue luego tomado por muchos honbres honrados

y en un vulto muy labrado

fue por todos sepultado con dos rétulos dorados. (copla núm. 40)

20 Mark Levenson, "Of Canines and Commandments" [www.torah.org/features/ firstperson/dogs.html]. Esta y el resto de traducciones del inglés en este ensayo son mías.

21 Sobre la nariz judía como uno de los rasgos físicos con que se representan a los judíos, a propósito de la aversión general del pueblo durante la época en que se publicaron las Coplas, véase María de los Ángeles Hermosilla Álvarez, op. cit., p. 163. 
El uno dellos dezía:

"aquí yaze el brauo can

que nunca comía pan,

saluo honbre o muger judía”.

El segundo que tenía,

dezía lo que se sigue:

"Aquí está un brauo león,

para judíos pasión,

cuya fama siempre biue”. (copla núm. 41)

Los exiliados vuelven a Alba de Tormes, pero el perro sigue hostigándolos desde la tumba, ladrando a cualquier judío o converso que se atreva a acercarse. Según el poema, el perro sobrevive en la memoria cristiana como héroe virtuoso y honrado: "Así el buen can feneció / con muy gran virtud y honra; / los judíos con deshonra / y vituperio dexó” (copla núm. 45). Por supuesto, tal "deshonra y vituperio" son el propósito de las Coplas, que están escritas precisamente para denigrar y erradicar metafóricamente a los judíos.

Por una parte, sorprende que este poema no haya recibido más atención crítica reciente, dada la actual fascinación con la España "multicultural" y su pasado. Por otra, el tipo de antisemitismo burlesco, pero no por ello menos despiadado, que muestra el texto es un recordatorio chocante de los prejuicios e interacciones problemáticas entre cristianos nuevos y viejos en la Espańa de su momento.

Vuelvo a la mención inicial de las Coplas que se encuentra en La elección de los alcaldes de Daganzo porque hay otro paralelo curioso con este poema y Cervantes. El judío Samuel de la primera obra testifica ante el juez que, cuando visita a su "amiga", el perro se interpone entre los amantes, levantando la alarma sobre sus aventuras amorosas:

Quando yo vo a ver mi amiga, ¡juro al Dió!, que me rasguña

e me mete en turbación con muy grande alteración, aunque le ruego no gruña. (copla núm. 8) 
Esta anécdota es muy parecida a un episodio del Coloquio de los perros: cuando Berganza vivía como guardián y mascota en casa de un rico mercader sevillano (probablemente converso), atacaba en silencio a una pareja de esclavos negros que se juntaban allí de noche. Como dice el perro: "bajando una noche muy escura a su acostumbrado pasatiempo, arremetí sin ladrar, porque no se alborotasen los de casa, y en un instante le hice pedazos toda la camisa y le arranqué un pedazo de muslo, burla que fue bastante a tenerla de veras más de ocho días en la cama [...]"22. Ya que evidentemente Cervantes conocía las Coplas, es razonable aventurar que la declaración de Samuel pudo haber inspirado este episodio, aunque comparar la magnífica novela cervantina con este poema ofensivo puede considerarse excesivo en extremo. Sin embargo, hay otra conexión en el hecho de que los dos perros sean alanos, una raza con merecida reputación de ferocidad. Eran mastines grandes y corpulentos (como se ve en el grabado), utilizados para el combate y el ataque, para controlar el ganado en los mataderos, agarrar toros y osos, como guardianes, y famosamente para la guerra en el Nuevo Mundo. Es muy revelador, entonces, que el diabólico perro de Alba pertenezca a esta temida raza.

Gillet menciona que existe otra versión de este poema, de 1578, que se titula "El pleito de los moriscos con el perro de Alua, / de la burla que les hizo. Agora nuevamente trobada, por el bachiller Iuan / de Trasmiera residente en Salamanca, la qual hizo a / ruego y pedimiento de vn señor. / En Barcelona año 1578”23. Esta versión precede a la expulsión de los moriscos en treinta y un años. ¿Qué podemos extraer de esta cronología? ¿Representan conversos y moriscos lo mismo para los satíricos cristianos viejos? ¿Son sencillamente otro grupo minoritario semítico despreciado y recelado? ¿Son arribistas mal vistos? En otras palabras, ¿son estas Coplas una sátira genérica que puede aplicarse a cualquier grupo social marginalizado y que funciona según sus propios estándares estéticos, convenciones y topoi, sean quienes sean los atacados? O, como razona María Cruz García de Enterría sobre las diferentes versiones que tienen como protagonista al famoso perro de Alba, avalando su intención satírica:

22 Miguel de Cervantes, Novelas ejemplares, II, ed. Harry Sieber, Madrid, Cátedra, 1982, p. 322.

23 Joseph E. Gillet, op. cit., p. 123. 
Durante el siglo XVII se difundieron más estas otras versiones, pero ellas mismas eran prueba de la constancia con que se mantenía en el pueblo el desprecio a los judíos que empujaba a tomarlos a chacota. Si ni siquiera los escritores de probada humanidad se veían libres de este prurito racista de atacar a los judíos y burlarse de ellos cruelmente, no es extraño que los autores e impresores de pliegos de cordel cayeran en lo mismo. Hugo de Mena, impresor de Granada, responsable último de todo el material que nos brindan los veinticinco pliegos de Cracovia, no podía ser una excepción ${ }^{24}$.

Aunque de manera grotesca, el poema sí trata a los judíos y conversos como tipos cómicos, fuente de hilaridad e irrisión que quizás sirva para disipar los miedos conectados con "los caracteres especialmente siniestros que proliferan en los escritos panfletarios" secentistas ${ }^{25}$.

Por supuesto es difícil apreciar hoy el tipo de humor anti-judaico y ramplón en que se basan estas Coplas. Sin embargo, los testigos que denuncian al perro se presentan de tal manera que se subvierte cualquier identificación, simpatía o compasión que el lector pueda sentir por ellos. Además, como ha apuntado Rowson, lo más probable es que para ser eficaces, estos tipos de burlas cuenten con una hostilidad social implícita o incluso explícita, y pueden demostrar precisamente dónde las actitudes resultan más intransigentes ${ }^{26}$. Por lo tanto, esta supuesta comicidad es en el fondo profundamente xenófoba.

Debemos además tener en mente tanto el género "literario" cuanto el receptor de este pliego de cordel en el momento de su producción y actuación. Como afirma María Cruz García de Enterría, con el pliego de cordel estamos ante una muestra de la cultura popular, lo cual a mi

24 María Cruz García de Enterría (ed.), Pliegos poéticos españoles de la Biblioteca Universitaria de Cracovia. Homenaje a Piotr Dunin Wolski, Madrid, Joyas Bibliográficas, 1975, p. 56.

25 Jesús-Antonio Cid, "Judíos en la prosa española del siglo XVII. Síntesis y antología”, en Judios en la literatura española, ed. Iacob M. Hassán, Cuenca, Universidad de Castilla-La Mancha, 2001, pp. 213-265 (p. 218).

26 Everett K. Rowson, "The Categorization of Gender and Sex Irregularity in Medieval Arabic Vice Lists", en Body Guards: The Cultural Politics of Gender Ambiguity, ed. Julia Epstein y Kristina Straub, New York, Routledge, 1991, p. 53. 
parecer problematiza el impacto extra-textual de este tipo de copla ${ }^{27}$. Estas obritas estaban destinadas mayoritariamente a la trasmisión oral cantada, y a un público ni culto ni probablemente alfabetizado. Además, las del Perro de Alba arrancan con unos versos iniciales bastante juglarescos: "En Alua estando el alcalde / juzgando muy retamente, / pareció infinita gente / de judíos, quasi embalde” (copla núm. 1), que suenan a lo que en años posteriores serían relaciones de sucesos y en épocas anteriores romances históricos y poemas épicos. La comparecencia de los querellantes y testigos ante el juez, y por consiguiente el auditorio, pone en evidencia su oralidad, al igual que el tono de épica burlesca, que aumenta con las noticias del perro-héroe después de su milagrosa fuga de la picota:

El perro, como se vio

de la picota colgado, con enojo muy ayrado como trompetas oyó, toda la soga quebró y asió luego del primero, del qual tan rezio mordió que incontinente murió aunque era espingardero. (copla núm. 34)

Los judíos, de espantados, cayeron amortecidos: unos rotos y mordidos, otros del todo finados. Luego fueron enterrados los que el perro degolló. Los que de espanto murieron en sus huesas [fosas] los pusieron y el perro en sagrado entró. (copla núm. 35)

27 María Cruz García de Enterría, "Pliegos de cordel, literaturas de ciego", en Culturas en la Edad de Oro, ed. José María Díez Borque, Madrid, Editorial Complutense, 1995, pp. 97-112 (pp. 98-99). 
El furor y las mortales mordidas épicas del perro, que inspiran tal terror en los judíos que caen muertos, no dejan de recordar los golpes épicos de los héroes caballerescos de los que precisamente se burlaba Cervantes en Don Quijote de la Mancha. Como aquellos, el perro de Alba es también indestructible y en vez de morir en batalla contra sus enemigos hebraicos, cae víctima de la peste, que no distinguía entre cristianos y judíos.

Es tremendamente sugestivo que la misantropía de este poema sea filtrada justo a través de un perro, el más domesticado de todos los animales, el compañero más íntimo del hombre y el que ha sido venerado por su lealtad. Sobre las relaciones entre humanos y canes, un campo crítico en pleno auge entre científicos, sociólogos y humanistas bajo la rúbrica de los estudios de animales (Animal Studies), el zoólogo James Herpell afirma que, con la posible excepción del simio, ningún otro animal se aproxima tanto al ser humano en términos simbólicos y afectivos como el perro, y ningún otro tiene más derecho a ser tratado como humano ${ }^{28}$. Por su parte, Aaron Herald Skabelund estudia las diversas funciones simbólicas del perro en la imaginería humana y en el imperialismo, notando que la gran plasticidad física de los canes, que resulta de su manipulación por el hombre, su intimidad con este y su papel como intermediario en las interacciones humanas, son factores que contribuyen a su flexibilidad simbólica ${ }^{29}$.

Y de todos los perros literarios de los Siglos de Oro españoles, el de Alba exhibe una identidad y mentalidad particularmente porosas y próximas a las del ser humano. Lo que tenemos aquí es un perro de ataque, un alano malevolente que quizás no muerde cuando se le manda, sino que ha internalizado los valores y prejuicios viejocristianos en tal grado que ataca por su cuenta ${ }^{30}$. Es este comportamiento "humano" lo que ensalza

28 James Serpell, "From Paragon to Pariah: Some Reflections on Human Attitudes towards Dogs", en The Domestic Dog: Its Evolution, Behaviour and Interactions with People, ed. James Serpell, Cambridge, Cambridge University Press, 1996, pp. 245-256.

29 Aaron Herald Skabelund, Empire of Dogs: Canines, Japan, and the Making of the Modern Imperial World, Ithaca, Cornell University Press, 2011, p. 7.

30 Discrepo de María Cruz García de Enterría, quien afirma en el estudio que precede a la edición en facsímil de los Pliegos poéticos españoles de la Biblioteca Universitaria de Cracovia que el perro ha sido "amaestrado para la persecución y ataque a los judíos”. Véase María Cruz García de Enterría, op. cit., p. 55. Puede ser que Antón 
el poema y lo que conducirá a la destrucción de la comunidad judía que existió en Alba de Tormes hasta 1492.

Las Coplas del perro de Alba, presuntamente de escaso mérito estéticoliterario pero de mayor valor como expresión satírica, son ejemplo del tipo de poesía que incomoda al lector hasta lo hondo y que los críticos prefieren evadir o descartar. Este azote simbólico de los judíos, paradójicamente vertido en forma del mayor amigo del hombre y que demuestra la permeabilidad ontológica a la que se refiere Skabelund al asegurar la voz poética que "a los christianos amaua / como persona discreta" (copla núm. 37), sirve particularmente para revelar la naturaleza compleja y problemática de las interacciones humanas en la España de la temprana época moderna.

Gentil haya amaestrado al perro, pero también, como afirmo, que ataque por su cuenta. De hecho, los testigos judíos no se querellan contra el dueño sino contra el mismo can. Todo ocurre en el reino metafórico, luego todo es posible. 